\title{
Characterization and genome analysis of a butanol-isopropanol-producing Clostridium beijerinckii strain BGS1
}

\author{
Chen Zhang, Tinggang Li and Jianzhong $\mathrm{He}^{*}$ (D)
}

\begin{abstract}
Background: One of the main challenges of acetone-butanol-ethanol fermentation is to reduce acetone production with high butanol yield. Converting acetone into isopropanol is an alternative pathway to reduce fermentation by-products in the fermentation broth. Here, we aimed to cultivate a wild-type Clostridium strain with high isopropanol and butanol production and reveal its genome information.
\end{abstract}

Results: Clostridium beijerinckii strain BGS1 was found to be capable of producing $10.21 \mathrm{~g} / \mathrm{L}$ butanol and $3.41 \mathrm{~g} / \mathrm{L}$ isopropanol, higher than previously known wild-type isopropanol-butanol-producing Clostridium species. Moreover, culture BGS1 exhibited a broad carbon spectrum utilizing diverse sugars such as arabinose, xylose, galactose, cellobiose, and sucrose, with $9.61 \mathrm{~g} / \mathrm{L}$ butanol and $2.57 \mathrm{~g} / \mathrm{L}$ isopropanol generated from $60 \mathrm{~g} / \mathrm{L}$ sucrose and less amount from other sugars. Based on genome analysis, protein-based sequence of strain BGS1 was closer to C. beijerinckii NCIMB 8052 , reaching $90.82 \%$ similarity, while compared to C. beijerinckii DSM 6423 , the similarity was $89.53 \%$. In addition, a unique secondary alcohol dehydrogenase (sAdhE) was revealed in the genome of strain BGS1, which distinguished it from other Clostridium species. Average nucleotide identity analysis identified strain BGS1 belonging to C. beijerinckii. The transcription profile and enzymatic activity of sAdhE proved its function of converting acetone into isopropanol.

Conclusions: Clostridium beijerinckii strain BGS1 is a potential candidate for industrial isopropanol and butanol production. Its genome provides unique information for genetic engineering of isopropanol-butanol-producing microorganisms.

Keywords: Isopropanol, Butanol, Clostridium beijerinckii, Genome, Secondary alcohol dehydrogenase

\section{Background}

Isopropanol and butanol are widely used in a variety of industrial applications including solvent applications, chemical intermediates and biofuels. When serving as a biofuel, butanol can be used as a fuel additive or completely replace gasoline due to property similarities [1], while isopropanol can replace methanol for biodiesel synthesis with reduced biodiesel crystallization temperature [2]. Additionally, isopropanol can partially replace gasoline so as to increase octane number of the fuels [3].

\footnotetext{
*Correspondence: jianzhong.he@nus.edu.sg
}

Department of Civil and Environmental Engineering, National University of Singapore, Block E2-02-13, 1 Engineering Drive 3, Singapore 117576 , Singapore
However, given that both chemicals are mainly produced from non-renewable petroleum-based materials, microbial production of isopropanol and butanol from renewable feedstock becomes more attractive and cost effective [4].

As a traditional microbial way to produce butanol, acetone-butanol-ethanol (ABE) fermentation by Clostridium species can generate butanol, acetone and ethanol at a ratio of 6:3:1 typically [5]. However, the main by-product, acetone, is not preferred because of its high corrosiveness to engine and low energy density [6]. Although acetone production have been tried to be reduced by knock-out of acetoacetate decarboxylase $(a d c)$ gene, butanol reduction and acetate accumulation inevitably occurred with the acetone reduction [7]. In

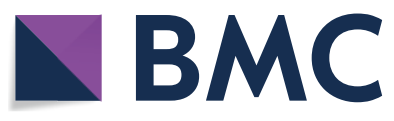

(c) The Author(s) 2018. This article is distributed under the terms of the Creative Commons Attribution 4.0 International License (http://creativecommons.org/licenses/by/4.0/), which permits unrestricted use, distribution, and reproduction in any medium, provided you give appropriate credit to the original author(s) and the source, provide a link to the Creative Commons license, and indicate if changes were made. The Creative Commons Public Domain Dedication waiver (http://creativecommons.org/ publicdomain/zero/1.0/) applies to the data made available in this article, unless otherwise stated. 
contrast, isopropanol-butanol-ethanol (IBE) fermentation by Clostridium species is a more preferred microbial pathway for both renewable butanol and isopropanol production without the undesirable acetone [8]. Compared to traditional $\mathrm{ABE}$ fermentation, IBE fermentation produces a component of isopropanol, an alcohol with slightly higher energy density than acetone $(23.9 \mathrm{MJ} / \mathrm{L}$ vs $22.6 \mathrm{MJ} / \mathrm{L}$ ), and the end-products of IBE mixture can be used directly as a green fuel in spark-ignition (SI) engines, usually with lower pollutant emissions and better engine performance than ABE mixture [9].

Among all the solvent-producing Clostridium strains, a few strains can produce butanol and isopropanol as major fermentation products, while most isopropanolproducing bacteria belong to Clostridium beijerinckii [10]. In general, most of the isopropanol-producing strains produce relatively low concentrations of butanol and isopropanol, less than $5.5 \mathrm{~g} / \mathrm{L}$ and $1.5 \mathrm{~g} / \mathrm{L}$, respectively, due to the toxicity posed by butanol $(>7.4 \mathrm{~g} / \mathrm{L})$ [11]. To produce isopropanol with ABE-producing Clostridium, an attempt has been made to engineer secondary alcohol dehydrogenase (sAdhE) gene from C. beijerinckii NRRL B-593 into non-isopropanol producing C. acetobutylicum [6]. However, the successful conversion of acetone into isopropanol also caused reduction of butanol yield. To date, only one $s A D H$ gene from C. beijerinckii NRRL B-593 with limited genome information was identified, while this wild-type strain produced quite low titers $(<5 \mathrm{~g} / \mathrm{L})$ of butanol and isopropanol [12]. Very recently, C. beijerinckii DSM 6423 [13] was also found to possess $s A d h E$ gene encoding enzymes for isopropanol and butanol production but with lower titers $(<10.7 \mathrm{~g} / \mathrm{L})$. Finding novel wild-type bacteria with higher isopropanol and butanol production as well as detailed genome information is of great interest for isopropanol and butanol biorefinery.

To broaden current knowledge of butanol and isopropanol production, this study aimed to (i) characterize an isopropanol-butanol-producing microorganism with high yield; (ii) analyze the genome of this strain and further identify functional genes responsible for isopropanol production.

\section{Results and discussion}

\section{Isolation and characterization of Clostridium sp. strain} BGS1

To discover novel isopropanol-butanol-producing microorganisms, soil samples from grass land were used as inocula for microcosm setup. After three transfers, four enriched cultures with butanol and isopropanol production were selected for further cultivation of individual colonies. Eight of well-grown colonies were picked up from deep agar medium spiked with $60 \mathrm{~g} / \mathrm{L}$ glucose
[14] and further transferred to fresh medium. Among all isolates, one culture designated BGS1 was identified to be capable of producing $3.88 \mathrm{~g} / \mathrm{L}$ butanol and $1.07 \mathrm{~g} / \mathrm{L}$ isopropanol with negligible amount of acetone and ethanol. When culture BGS1 was observed under light microscopy, the uniform rod-shaped morphology suggested the purity of the culture. The sequence of the 16S rRNA gene from culture BGS1 showed 99\% identity to $C$. beijerinckii strain TERI-Chilika-02 based on Blast results. When comparing with 12 previously reported bacteria capable of producing butanol or isopropanol, culture BGS1 exhibited closer similarity to strains under C. beijerinckii (Fig. 1a). However, phylogenetic tree based on 16S rRNA gene can only identify microorganisms to genus level. Based on the genome information, average nucleotide identity (ANI) was applied to identify the species of strain BGS1 [15]. ANI of 95\% between two bacterial genomes usually corresponds to 70\% DNA-DNA hybridization value, from which it can confirm the two bacteria belonging to the same species [16]. As shown in Fig. 1b, cluster heatmap of ANI analysis clearly depicted that Clostridium sp. BGS1 clusters to C. beijerinckii species, of which all ANI values were higher than $96 \%$ of similarity but were lower than $80 \%$ of ANI values comparing with other Clostridium species. Hence, this isolate is designated C. beijerinckii strain BGS1.

Clostridium beijerinckii strain BGS1 distinguishes itself from other known $C$. beijerinckii strains by its high isopropanol production. As a typical C. beijerinckii strain, NCIMB 8052 mainly produced butanol and ethanol with acetone as a by-product, but was not able to produce isopropanol using glucose as a substrate [17]. Therefore, this newly isolated wild-type solvent-producing C. beijerinckii BGS1 broadens the pool of isopropanol-butanolproducing species [18].

\section{Optimization of fermentation conditions for enhanced butanol and isopropanol production}

During the solvent fermentation, $\mathrm{pH}$ was a key factor influencing fermentation performance [5]. To optimize $\mathrm{pH}$, five batch experiments were conducted at different $\mathrm{pH}$ conditions (5.0, 5.2, 5.5, 5.8, 6.5). $\mathrm{pH}$ was adjusted to a defined value by $3 \mathrm{M} \mathrm{NaOH}$ in every $12 \mathrm{~h}$. After 3 days of incubation, culture BGS1 generated higher amount of butanol at $\mathrm{pH} 5.0(5.00 \mathrm{~g} / \mathrm{L}), \mathrm{pH} 5.2(4.46 \mathrm{~g} / \mathrm{L})$ and $\mathrm{pH} 5.5$ $(4.11 \mathrm{~g} / \mathrm{L})$, and lower amount at $\mathrm{pH} 5.8(3.53 \mathrm{~g} / \mathrm{L})$ and $\mathrm{pH}$ $6.5(1.93 \mathrm{~g} / \mathrm{L})$, while similar amounts of isopropanol were obtained at varied $\mathrm{pH}$ conditions. In addition, high $\mathrm{pH}$ (6.5) led to significantly increased acetic acid (6.36 g/L) and butyric acid $(6.67 \mathrm{~g} / \mathrm{L})$ production in the fermentation broth, indicating that it was difficult for strain BGS1 to shift from acidogenesis to solventogenesis when $\mathrm{pH}$ is higher than 5.8. Therefore, maintaining a $\mathrm{pH}$ range 

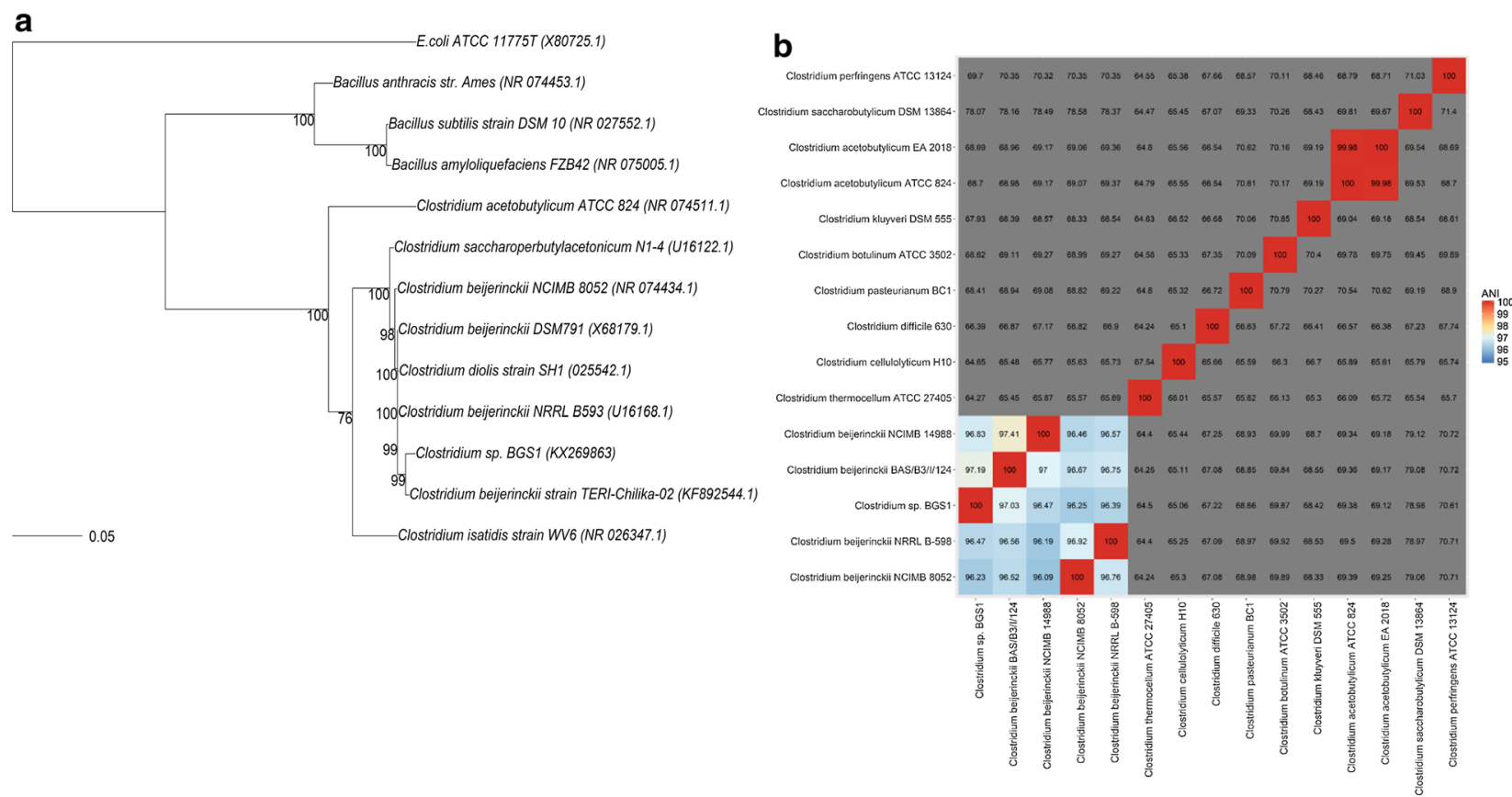

Fig. 1 a Phylogenetic tree by maximum likelihood method based on the GTR + G model, b cluster heatmap of Clostridium beijerinckii BGS1 based on ANI calculation results

from 5.0 to 5.5 is necessary to boost cell growth and early shift to solventogenesis. After $\mathrm{pH}$ optimization, $3 \mathrm{~g} / \mathrm{L}$ yeast extract was supplemented to the medium, in which $6.50 \mathrm{~g} / \mathrm{L}$ butanol and $3.01 \mathrm{~g} / \mathrm{L}$ isopropanol were generated, the enhancement of which could be caused by yeast extract to maximize cell growth [19].

To further improve solvents production, eight factors potentially influencing fermentation performance were selected as supplement to the medium. The heatmap of Pearson correlation coefficient between end-products and factors is shown in Fig. 2a. Among all eight factors, supplementation of nicotine acid did not obviously increase butanol and isopropanol production compared to that of control. In comparison, $\mathrm{Zn}^{2+}$ and $\mathrm{Ca}^{2+}$ showed strong positive correlation with isopropanol; while $\mathrm{Fe}^{2+}$, $\mathrm{Zn}^{2+}, \mathrm{Ca}^{2+}$ and butyrate exhibited strong positive correlation with butanol. However, given that butyrate was negatively correlated with isopropanol production, it was not considered as a beneficial factor; thus, $\mathrm{Fe}^{2+}, \mathrm{Zn}^{2+}$ and $\mathrm{Ca}^{2+}$ were finally selected as enhancement factors to improve butanol and isopropanol production.

Subsequently, a response surface methodology (RSM) based on central composite design (CCD) by Design Expert version 8.0 was used to obtain optimized fermentation conditions [20]. According to the results of 20 experiments, the optimal condition was confirmed

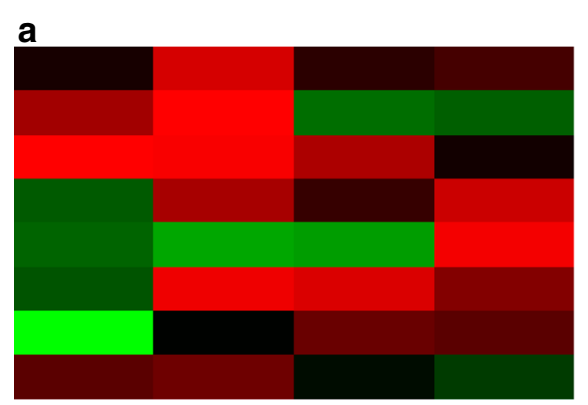

Isopropanol Butanol Acetic acid Butyric acid

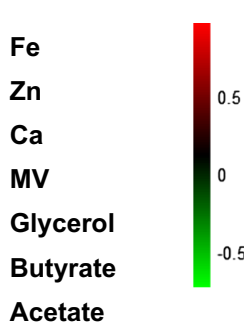

Acetate

Nicotine acid

Fig. 2 Heatmap of Pearson correlation coefficient of end-products and influence factors in medium containing a $60 \mathrm{~g} / \mathrm{L}$ glucose, $\mathbf{b} 60 \mathrm{~g} / \mathrm{L}$ sucrose 
at $\mathrm{Zn}^{2+}$ of $8 \mathrm{mg} / \mathrm{L}, \mathrm{Fe}^{2+}$ of $2 \mathrm{mg} / \mathrm{L}$ and $\mathrm{CaCO}_{3}$ of $5 \mathrm{~g} / \mathrm{L}$; thus, with $3 \mathrm{~g} / \mathrm{L}$ yeast extract and the abovementioned three elements supplemented, culture BGS1 was capable of producing $10.21 \mathrm{~g} / \mathrm{L}$ butanol and $3.41 \mathrm{~g} / \mathrm{L}$ isopropanol (Fig. 3a). Clostridium beijerinckii BGS1 produced highest amount of butanol and third highest amount of isopropanol as compared to those of previously reported wild-type isopropanol-butanol-producing Clostridium (Table 1).

Clostridium beijerinckii strain BGS1 ferments diverse sugars Clostridium beijerinckii strain BGS1 was assayed on its capability of fermenting various sugars (Fig. 4). For monosaccharides, in reduced mineral salts medium containing $3 \mathrm{~g} / \mathrm{L}$ yeast extract, culture BGS1 was capable of producing $3.96,7.81$ or $1.45 \mathrm{~g} / \mathrm{L}$ butanol, and $0.23,1.65$ or $0.44 \mathrm{~g} / \mathrm{L}$ isopropanol when fed with $60 \mathrm{~g} / \mathrm{L}$ xylose, arabinose or galactose, respectively. Although both xylose and arabinose belong to pentose, culture BGS1 can utilize arabinose much better than xylose, and produce similar amounts of butanol and isopropanol as compared to those with glucose as a carbon source. Strain BGS1 produced larger amount of acetic acid when fed with arabinose or xylose than glucose, indicating longer acidogenesis phase with pentose as a substrate. When galactose was used as a sole carbon source, culture BGS1
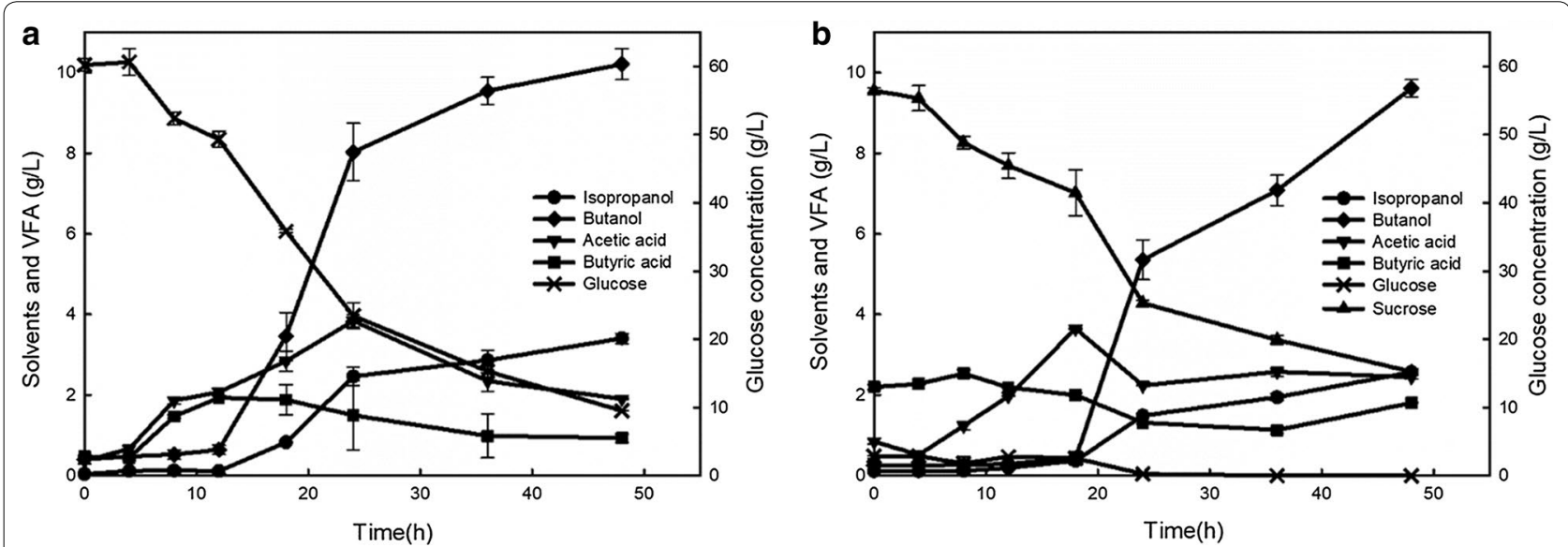

Fig. 3 Optimized solvents production of Clostridium beijerinckii strain BGS1 in reduced mineral salts medium containing a $60 \mathrm{~g} / \mathrm{L}$ glucose with $3 \mathrm{~g} / \mathrm{L}$ yeast extract, $5 \mathrm{~g} / \mathrm{L} \mathrm{CaCO}_{3}, 8 \mathrm{mg} / \mathrm{L} \mathrm{Zn}^{2+}$ and $2 \mathrm{mg} / \mathrm{L} \mathrm{Fe}^{2+}, \mathbf{b} 60 \mathrm{~g} / \mathrm{L}$ sucrose with $3 \mathrm{~g} / \mathrm{L}$ yeast extract, $1 \mathrm{~g} / \mathrm{L} \mathrm{CaCO}, 3 \mathrm{~g} / \mathrm{L}$ sodium butyrate, and $6 \mathrm{mg} / \mathrm{L}$ $\mathrm{Fe}^{2+}$

Table 1 Comparison of various wild-type isopropanol-butanol-producing wild-type strains

\begin{tabular}{|c|c|c|c|c|}
\hline References & Substrate & Strain & Isopropanol (g/L) & Butanol (g/L) \\
\hline P. G. Krouwel & glucose $57 \mathrm{~g} / \mathrm{L}$ & Clostridium butylicum LMD 27.6 & 2.83 & 5.25 \\
\hline P. G. Krouwel & glucose $20 \mathrm{~g} / \mathrm{L}$ & Clostridium beijerinckii LMD 27.6 & 1.33 & 3.95 \\
\hline J.S. CHEN & glucose $60 \mathrm{~g} / \mathrm{L}$ & Clostridium beijerinckii VPI2968 & 0.12 & 3.06 \\
\hline J. S. CHEN & glucose $60 \mathrm{~g} / \mathrm{L}$ & Clostridium beijerinckii VPI2968 & 0.59 & 3.32 \\
\hline J. S. CHEN & glucose $60 \mathrm{~g} / \mathrm{L}$ & Clostridium aurantibutylicum NCIB 10659 & 0.60 & 4.24 \\
\hline J.S. CHEN & glucose $60 \mathrm{~g} / \mathrm{L}$ & Clostridium beijerinckii B-593 & 0.48 & 4.57 \\
\hline Stephen F. Hiu & glucose $60 \mathrm{~g} / \mathrm{L}$ & Clostridium beijerinckii NRRL B593 & 0.48 & 4.59 \\
\hline Stephen F. Hiu & glucose $60 \mathrm{~g} / \mathrm{L}$ & Clostridium beijerinckii ATCC 6014 & 1.08 & 4.89 \\
\hline Stephen F. Hiu & glucose $60 \mathrm{~g} / \mathrm{L}$ & Clostridium beijerinckii McClung 3081 & 1.56 & 6.00 \\
\hline Masatoshi Matsumura & cane molasses $50 \mathrm{~g} / \mathrm{L}$ & Clostridium isopropylicum IAM 19239 & 4.60 & 8.30 \\
\hline Shrikant A. Survase & glucose $60 \mathrm{~g} / \mathrm{L}$ & Clostridium beijerinckii DSM 6423 & 2.16 & 3.71 \\
\hline Truus de Vrije & glucose $40 \mathrm{~g} / \mathrm{L}$ xylose $20 \mathrm{~g} / \mathrm{L}$ & Clostridium beijerinckii NRRL B593 & 3.20 & 6.90 \\
\hline Sung Hun Youn & glucose $60 \mathrm{~g} / \mathrm{L}$ & Clostridium sp. A1424 & 4.49 & 9.43 \\
\hline Ying Yang & glucose $30 \mathrm{~g} / \mathrm{L}$ & Clostridium beijerinckii sp. optinoii & 3.21 & 6.24 \\
\hline This study & glucose $60 \mathrm{~g} / \mathrm{L}$ & Clostridium beijerinckii BGS1 & 3.41 & 10.21 \\
\hline This study & sucrose $60 \mathrm{~g} / \mathrm{L}$ & Clostridium beijerinckii BGS1 & 2.51 & 9.79 \\
\hline
\end{tabular}



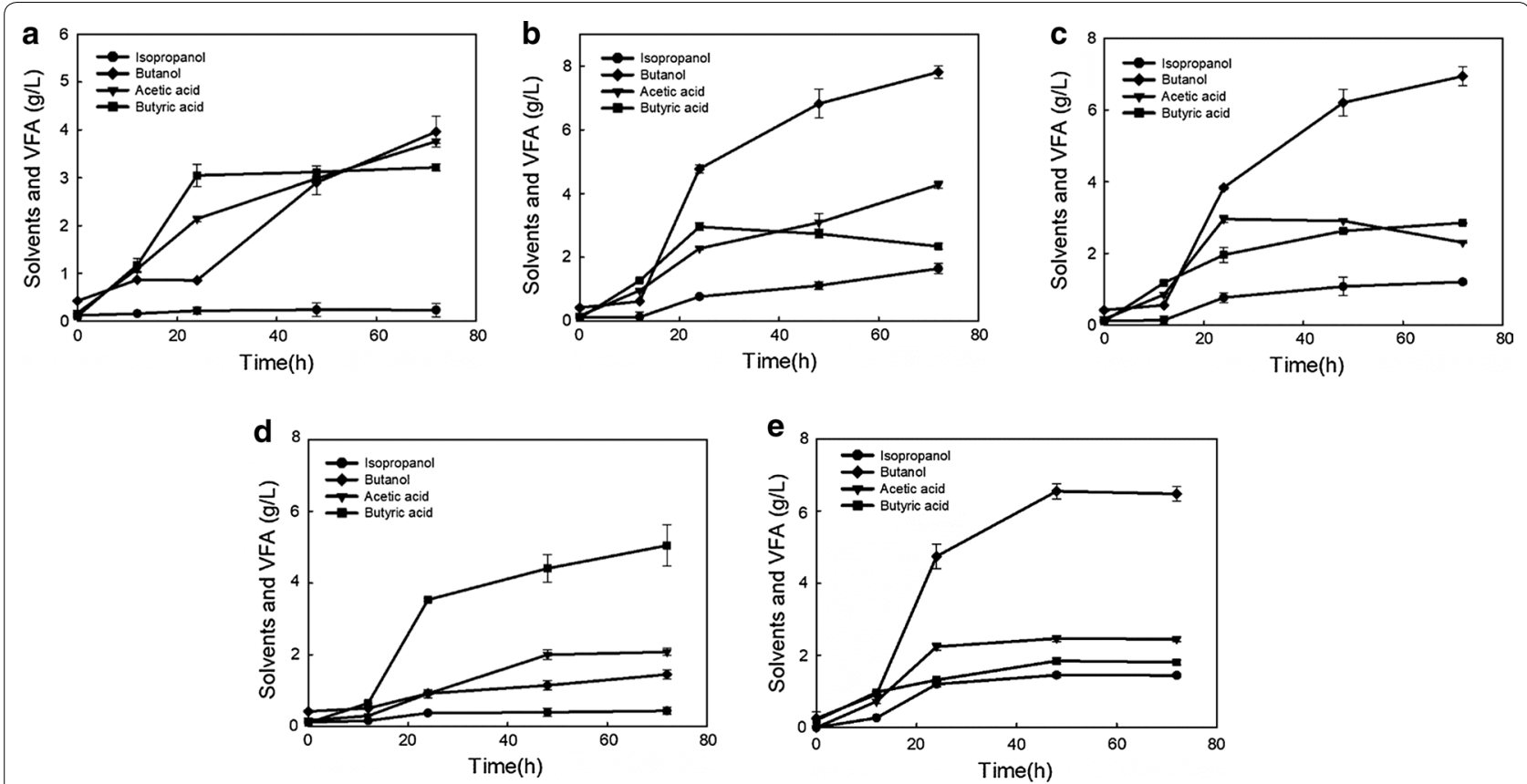

Fig. 4 Solvents production by Clostridium beijerinckii strain BGS1 in reduced mineral salts medium containing $3 \mathrm{~g} / \mathrm{L}$ yeast extract and a $60 \mathrm{~g} / \mathrm{L}$ xylose, b $60 \mathrm{~g} / \mathrm{L}$ arabinose, $\mathbf{c} 60 \mathrm{~g} / \mathrm{L}$ cellobiose, $\mathbf{d} 60 \mathrm{~g} / \mathrm{L}$ galactose, e $60 \mathrm{~g} / \mathrm{L}$ sucrose

produced low concentrations of butanol and isopropanol, but with the highest butyric acid among six carbon sugars tested (Fig. 4d), suggesting an additional pathway from galactose to glycolysis involved in C. beijerinckii BGS1 [21]. Since galactose cannot be directly used for glycolysis, the low amount of butanol could be caused by Leloir pathway from galactose to glucose-6-phosphatase, which slowed down glycolysis step to the following acidogenesis and solventogenesis phases. Compared to another isopropanol- and butanol-producing strain Clostridium sp. A1424, strain BGS1 demonstrated its potential in utilizing pentose to produce more valued products since Clostridium sp. A1424 only produced acetic acid and butyric acid as final products from xylose and arabinose [22].

In addition to monosaccharides, strain BGS1 showed efficient utilization of oligosaccharides. Cellobiose, a disaccharide consisting of two glucose molecules, is derived from cellulose or cellulose-rich materials. When fed with cellobiose, culture BGS1 produced $6.94 \mathrm{~g} / \mathrm{L}$ butanol and $1.21 \mathrm{~g} / \mathrm{L}$ isopropanol (Fig. 4c). It is speculated that culture BGS1 possesses glucosidase genes responsible for hydrolyzing cellobiose to glucose. Additionally, culture BGS1 was capable of utilizing another disaccharide-sucrose to produce $6.48 \mathrm{~g} / \mathrm{L}$ butanol and $1.44 \mathrm{~g} / \mathrm{L}$ isopropanol (Fig. 4e). Since sucrose consists of glucose and fructose (furanoid-like xylose), strain BGS1 may prefer glucose to fructose due to the carbon catabolite repression [23], which led to slightly lower butanol generation from sucrose than from cellobiose. To enhance utilization of sucrose, optimization studies via spiking $\mathrm{Fe}^{2+}, \mathrm{Zn}^{2+}, \mathrm{Ca}^{2+}$, or butyrate to the fermentation medium with sucrose were conducted, of which results showed that $\mathrm{Zn}^{2+}$ did not affect butanol and isopropanol production. Collectively, culture BGS1 was capable of producing $9.61 \mathrm{~g} / \mathrm{L}$ butanol and $2.57 \mathrm{~g} / \mathrm{L}$ isopropanol from $60 \mathrm{~g} / \mathrm{L}$ sucrose with addition of $1 \mathrm{~g} / \mathrm{L} \mathrm{CaCO}_{3}, 3 \mathrm{~g} / \mathrm{L}$ sodium butyrate, $6 \mathrm{mg} / \mathrm{L} \mathrm{Fe}^{2+}$ to the medium (Fig. $3 \mathrm{~b}$ ). Since $C$. beijerinckii strain BGS1 can utilize multiple sugars, it is a potential candidate for industrial strain to ferment plant-based hydrolysate.

\section{Genome analysis of $C$. beijerinckii strain BGS1}

To further explore the metabolic pathway of strain BGS1, the draft genome and functional annotation of strain BGS1 are illustrated here. The draft genome size of strain BGS1 is $5,880,896$ bp with a low GC content of $29.71 \%$. Based on annotation analysis, the genome of strain BGS1 contains 5223 predicted genes and the total length of genes is $4,721,271 \mathrm{bp}$, accounting for $80.28 \%$ of the whole draft genome. Additionally, the 5223 genes consist of 5008 coding sequences (CDSs), 99 tRNA genes, 28 rRNAs (including $115 \mathrm{~S}$ rRNAs, 5 16S rRNAs, and 12 $23 \mathrm{~S}$ rRNAs) and 6 ncRNAs. Among the CDSs, subsystem functions according to RAST analysis indicate that a total of 704 CDSs are involved in the carbohydrates 
subsystems, in which fermentation subsystems and central carbohydrate metabolism contain 100 CDSs and 135 CDSs, respectively. For the related products and intermediates, 29 CDSs are related to fatty acid synthesis and 21 CDSs are related to NAD and NADP cofactor synthesis.

Further analysis of genome comparison revealed pathway specificity. A total of 54 CDSs are involved in the fermentation pathway [4] from pyruvate to final products including solvents (butanol and isopropanol) and VFAs (Fig. 5). Among 16 alcohol dehydrogenase-related CDSs, four $B d h E$ genes encoding butanol dehydrogenase could be responsible for butanol production and one $s A d h E$ gene encoding isopropanol dehydrogenase may result in the conversion from acetone into isopropanol. Compared to C. beijerinckii NCIMB 8052 and isopropanolbutanol-producing strain C. beijerinckii DSM 6423 [13], the number of CDSs related to metabolic pathway in BGS1 genome is more than that of DSM 6423 (a total of 45 CDSs) but is similar to that of NCIMB 8052 (a total of 56 CDSs). The most significant difference among these
CDSs in the three strains is the $s A d h E$ gene. The expression of $s A d h E$ gene results in the production of isopropanol by BGS1 and DSM 6423 while in NCIMB 8052, the lack of $s A d h E$ gene terminates further conversion of acetone into isopropanol. The $s A d h E$ gene of BGS1 exhibited $90 \%$ (953/1056) similarity with that of DSM 6423. However, the function based on annotation showed that both are NADP-dependent and $\mathrm{Zn}$-dependent alcohol dehydrogenases, which may correspond to isopropanol production improvement by $\mathrm{Zn}$.

In addition to nucleotide-based sequence comparison, protein-based comparison between C. beijerinckii BGS1 and two strains (strain DSM 6423 and NCIMB 8052) was also analyzed. As visualized in Fig. 6, similar protein sequence between BGS1 and reference strain was linked by curves and their similarity was distinguished by color range [24]. The larger yellow area in Fig. 6a demonstrated lower protein sequence similarity between BGS1 and DSM 6423 compared to the similarity between BGS1 and NCIMB 8052. Also, the average similarity between

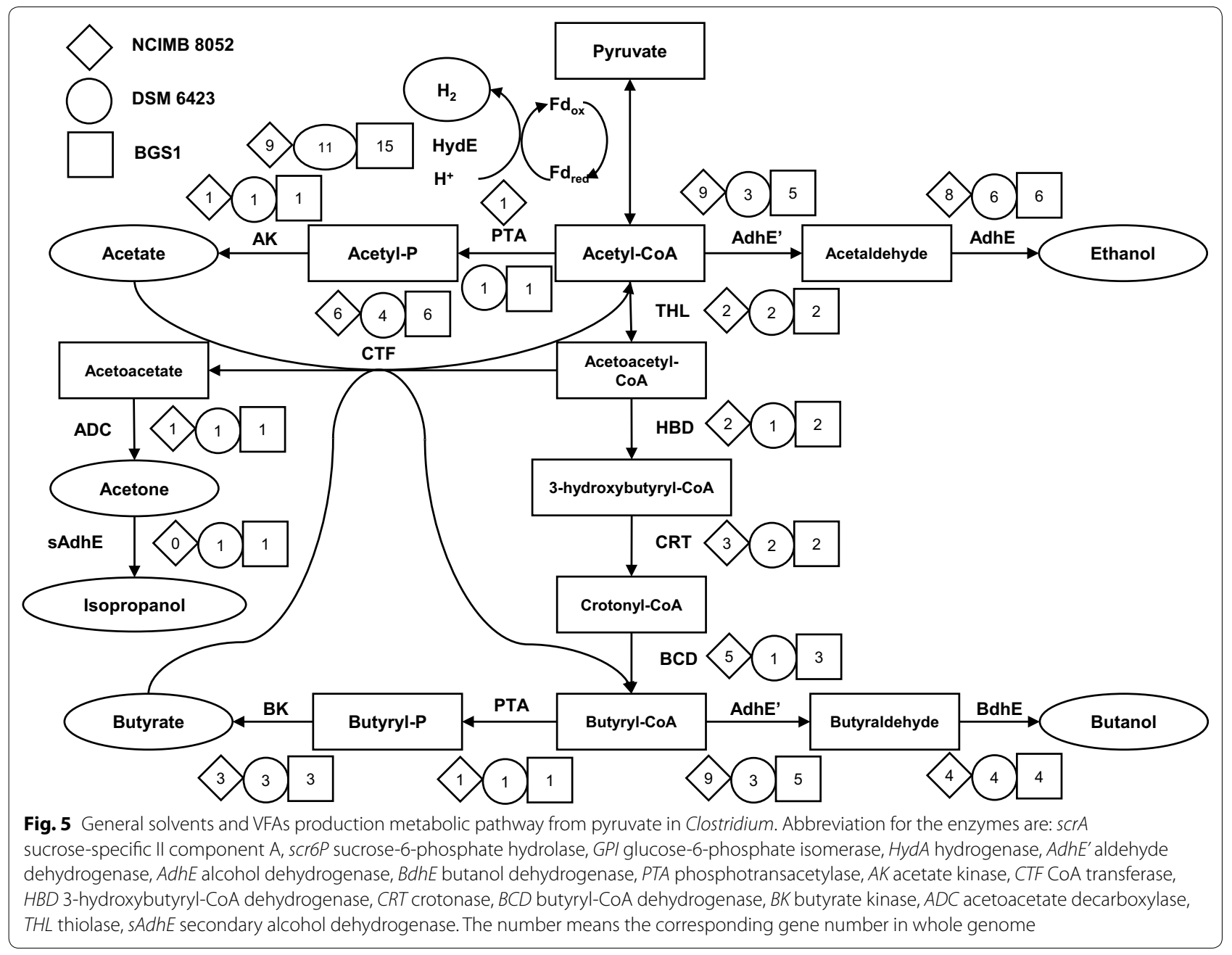



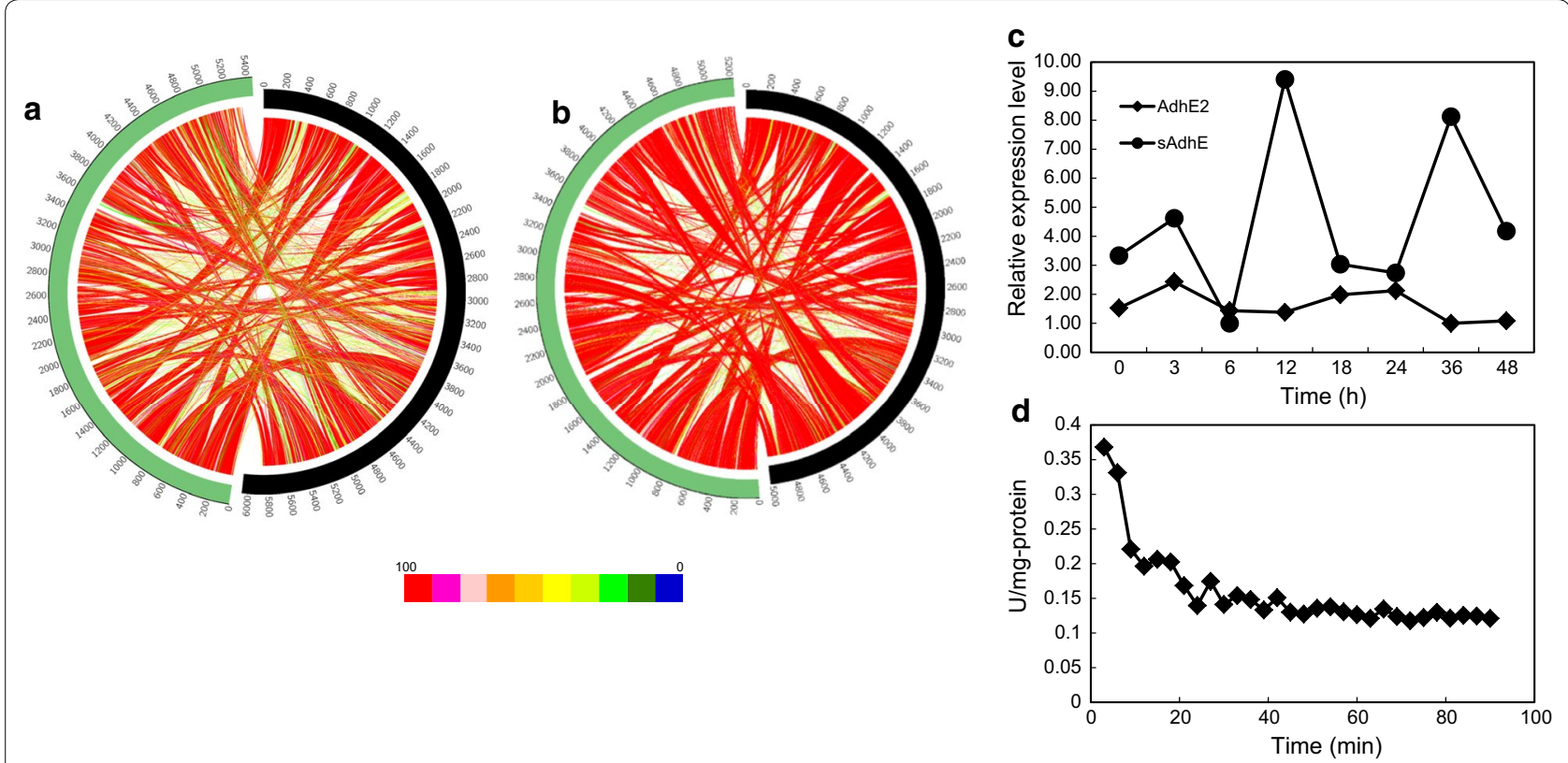

Fig. 6 a Protein-based sequence comparison between BGS1 (green) and DSM 6423 (black). b Protein-based sequence comparison between BGS1 (green) and NCIMB 8052 (black). c Gene expression level of sAdhE and AdhE2. d Enzyme activity of sAdhE

Table 2 Protein function similarity among Clostridium beijerinckii BGS1, DSM 6423 and NCIMB 8052

\begin{tabular}{lll}
\hline & BGS1 and DSM 6423 & $\begin{array}{l}\text { BGS1 } \\
\text { and NCIMB } \\
\mathbf{8 0 5 2}\end{array}$ \\
\hline Similarity & $94.96 \%$ & $76.23 \%$ \\
Unique protein in BGS1 & $2.55 \%$ & $3.99 \%$ \\
Unique protein in DSM 6423 & $2.49 \%$ & - \\
Unique protein in NCIMB 8052 & - & $19.78 \%$ \\
\hline
\end{tabular}

BGS1 and DSM 6423 was 89.53\%, while between BGS1 and DSM 8052 was $90.82 \%$. Additionally, protein function similarity among BGS, NCIMB 8052 and DSM 6423 provided different results (Table 2). BGS1 and DSM 6423 had $94.96 \%$ same protein function, while BGS1 and NCIMB 8052 only had $76.23 \%$ same protein function. The specific protein function was similar between BGS1 and DSM 6423. In contrast, NCIMB 8052 accounted for high percentage of specific protein function. Therefore, the two isopropanol-butanol-producing strains have closer protein function.

To confirm whether the identified $s A d h E$ gene was expressed in strain BGS1, the transcriptional expression of $s A d h E$ gene were quantified by qPCR, Fig. 6c showed that the expression of $s A d h E$ gene which reached to a peak after $\sim 12 \mathrm{~h}$ of incubation. Interestingly, although expression of $s A d h E$ gene gradually dropped after $\sim 18$-h incubation, it peaked again after $\sim 36 \mathrm{~h}$. Hence, it could be speculated that $s A d h E$ gene was independently expressed at early-exponential and solventogenic phases. To prove this hypothesis, acetone was supplemented to culture. Results showed that acetone was converted into isopropanol and the amount of isopropanol increased twice. Given that gene expression cannot confirm the positive activity of enzyme, the enzymatic activity of sAdhE was conducted and it reached $0.12 \mathrm{U} / \mathrm{mg}$ protein (Fig. 6d). Additionally, one of the $A d h E$ genes-AdhE2, was not obviously transcribed (Fig. 6c). Considering the fact that negligible ethanol was produced by culture BGS1, AdhE2 gene may be responsible for ethanol production. Negligible expression of $A d h E 2$ resulted in non-ethanol production of culture BGS1.

\section{Conclusions}

In this study, a wild-type C. beijerinckii BGS1 was identified to be capable of producing 10.21 or $9.61 \mathrm{~g} / \mathrm{L}$ butanol and 3.41 or $2.57 \mathrm{~g} / \mathrm{L}$ isopropanol from $60 \mathrm{~g} / \mathrm{L}$ glucose or sucrose, respectively, higher than previously reported wild-type isopropanol-butanol-producing Clostridium. Moreover, the genome of strain BGS1 distinguished it from other Clostridium species. This study offers a promising butanol-isopropanol-producing strain due to its (i) capability of high butanol and isopropanol production from diverse saccharides; (ii) negligible ethanol and acetone production towards simple post-treatment process; 
(iii) novel $s A d h E$ gene as a candidate for metabolic engineering of isopropanol production.

\section{Methods}

\section{Culture isolation and characterization}

Grassland soil samples from Mongolia were used as inocula for screening isopropanol-butanol-producing microorganisms. Reduced mineral salts medium was used as basic medium for isolation and batch fermentation, which contained $0.75 \mathrm{~g} / \mathrm{L}$ of $\mathrm{K}_{2} \mathrm{HPO}_{4}, 0.75 \mathrm{~g} / \mathrm{L}$ of $\mathrm{KH}_{2} \mathrm{PO}_{4}, 20 \mathrm{mM}$ (2-N-morpholino ethanesulfonic acid) (MES), and $1 \mathrm{~mL}$ of trace element solution, $10 \mathrm{~mL}$ salt solution and $1 \mathrm{~mL}$ of $\mathrm{Na}_{2} \mathrm{SeO}_{3}-\mathrm{Na}_{2} \mathrm{WO}_{4}$ solution to $1 \mathrm{~L}$ solution with reductants of $0.2 \mathrm{mM} \mathrm{Na}_{2} \mathrm{~S}, 0.2 \mathrm{mM}$ L-cysteine and $0.5 \mathrm{mM}$ DL-dithiothreitol [25]. After the medium was autoclaved for $20 \mathrm{~min}$ and cooled down to room temperature, a $50 \mathrm{~mL}$ medium with approximately $10 \mathrm{~mL}$ slurry soil and $60 \mathrm{~g} / \mathrm{L}$ glucose were added to $160 \mathrm{~mL}$ bottles sealed with butyl stoppers. The microcosm was incubated at $35{ }^{\circ} \mathrm{C}$ and transferred five times for further isolation. The enriched culture was diluted and dispensed in $20 \mathrm{~mL}$ bottles containing the reduced mineral salts medium plus agar. The bottles were spiked with $60 \mathrm{~g} / \mathrm{L}$ glucose and incubated at room temperature for individual colony growing. Individual colony was then picked and re-inoculated into $30 \mathrm{~mL}$ mineral salts medium fed with $60 \mathrm{~g} / \mathrm{L}$ glucose. All colonies were randomly selected, and the products were monitored by GC-FID. Among several butanol-producing anaerobic bacteria, an isopropanol-butanol-producing strain (designated BGS1) was obtained.

Genomic DNA of culture BGS1 was extracted and purified with DNeasy Tissue Kit (Qiagen, Germany) according to the manufacture's protocol. The 16S rRNA gene of strain BSG1 was amplified with a pair of universal bacterial primer 8F (5'-AGAGTTTGATCCTGGCTC AG-3') and 1392R (5'-ACGGGCGGTGTGT-3') [25]. The obtained PCR products were purified with a PCR Purification Kit (Qiagen, Germany) and sequenced using an ABI DNA sequencer (Applied Biosystems, USA). The obtained 16S rRNA gene sequence was analyzed by basic local alignment search tool (BLAST). The nucleotide sequence of culture BGS1 was deposited in GenBank under an accession number KX269863.

\section{Growth condition and optimization of culture BGS1}

Time-course studies of culture BGS1 were conducted in the mineral salts medium as described above. Cultures for inoculation were grown in the medium containing $60 \mathrm{~g} / \mathrm{L}$ glucose or other carbon sources (monosaccharides, disaccharides and polysaccharides) for $\sim 24 \mathrm{~h}$. Then, $6 \mathrm{~mL}$ inocula was added into $54 \mathrm{~mL}$ mineral salts medium in $160 \mathrm{~mL}$ serum bottles, in which the culture was incubated in a shaker at $35^{\circ} \mathrm{C}$ with a shaking speed of $130 \mathrm{rpm}$. $\mathrm{NaOH}(3 \mathrm{M})$ was applied to adjust $\mathrm{pH}$ to 5.5. To optimize the growth condition for culture BGS1, different $\mathrm{pH}(4.5,5.0,5.2,5.5,5.8,6.5)$ and nine ingredients possibly influencing fermentation performance (nicotinic acid, acetic acid, butyric acid, yeast extract, $\mathrm{Ca}^{2+}, \mathrm{Fe}^{2+}, \mathrm{Zn}^{2+}$, methyl viologen, glycerol) were tested. Nicotine acid $(0-20 \mathrm{mg} / \mathrm{L})$ and butyrate $(0-5 \mathrm{~g} / \mathrm{L})$ are the precursors of reducing cofactor NADH and butanol, respectively. Supplementation of acetate $(0-5 \mathrm{~g} / \mathrm{L})$ was able to induce early solventogenesis phase to produce solvents [26]. $\mathrm{CaCO}_{3}(0-7 \mathrm{~g} / \mathrm{L})$ had ability to enhance butanol tolerance by stabilizing membrane proteins and increased buffering capacity [27]. Glycerol (0-120 g/L) supplemented to medium containing glucose was reported to enhance cell growth and butanol production [28]. $\mathrm{Zn}^{2+}(0-10 \mathrm{mg} / \mathrm{L}), \mathrm{Fe}^{2+}$ $(0-8 \mathrm{mg} / \mathrm{L})$ and methyl viologen (MV) $(0-10 \mathrm{mg} / \mathrm{L})$ were considered as co-factors to improve solvents production [29]. Experiments were carried out in duplicates.

\section{Data analysis methods}

To acquire optimal fermentation conditions influenced by various factors, analysis was completed by response surface method (RSM) [20]. Concentrations of butanol and isopropanol were selected as dependent variables and influencing factors were independent variables. Central composite design (CCD) was chosen to apply RSM using Design Expert version 8.0 [30]. A secondorder polynomial equation for the response variables was built:

$$
Y_{\mathrm{i}}=\beta_{0}+\sum \beta_{\mathrm{i}} x_{\mathrm{i}}+\sum \beta_{\mathrm{ii}} x_{\mathrm{ii}}^{2}+\int \beta_{\mathrm{ij}} x_{\mathrm{i}} x_{\mathrm{j}},
$$

where $Y_{\mathrm{i}}$ is the predicted response; $x_{\mathrm{i}}, x_{\mathrm{j}}$ are independent variables which influence the dependent variable $Y$; $\beta_{0}$ is the offset term; $\beta_{\mathrm{i}}$ is the ith linear coefficient; $\beta_{\mathrm{ii}}$ is the ith quadratic coefficient; and $\beta_{\mathrm{ij}}$ is the ijth interaction coefficient.

All statistical analysis, phylogenetic tree, heatmap analysis and species cluster were addressed with $\mathrm{R}$ and the Bioconductor [31, 32]. Phylogenetic tree was analyzed using phangorn package [33]. Best tree model was selected by "bestmodel" command and phylogenetic tree was built by 1000 bootstrap. Pearson correlation coefficient was calculated on between duplicate factors concentration and concentrations of two products (butanol and isopropanol). Heatmap of Pearson correlation coefficient was drawn by pheatmap package [34]. Hierarchical 
cluster analysis was determined by the distance of all species from results of ANI analysis, which formed the ANI cluster heatmap.

\section{Analytic methods}

Fermentation broth $(1 \mathrm{~mL})$ was centrifuged at $12,000 \times g$ for $10 \mathrm{~min}$ at $4{ }^{\circ} \mathrm{C}$ and the resultant supernatant was stored at $-20^{\circ} \mathrm{C}$ until further analysis of the fermentation products. The solvents and fatty acids were measured by a gas chromatography (GC, model 7890A; Agilent Technologies, U.S.A.) equipped with a Durabond (DB)-WAXetr column $(30 \mathrm{~m} \times 0.25 \mathrm{~mm} \times 0.25 \mu \mathrm{m}$; I\&W, U.S.A. $)$ and a flame ionization detector (FID). The oven temperature was initially held at $60{ }^{\circ} \mathrm{C}$ for $2 \mathrm{~min}$, increased at $15{ }^{\circ} \mathrm{C} /$ min to $230{ }^{\circ} \mathrm{C}$, and held for $1.7 \mathrm{~min}$. Helium was used as the carrier gas with a column flow rate of $1.5 \mathrm{~mL} / \mathrm{min}$. Five-point standard curves were determined by standard solutions containing isopropanol, butanol, ethanol, acetone, butyric acid and acetic acid with concentrations ranging from 2 to $16 \mathrm{~g} / \mathrm{L}$. A high-performance liquid chromatograph (HPLC, model 1260 Infinity; Agilent Technologies, U.S.A) was used to measure concentrations of glucose and xylose with an Agilent Zorbax Carbohydrate Analysis column $(4.6 \mathrm{~mm} \times 150 \mathrm{~mm}, 0.5 \mu \mathrm{m})$ and a refractive index detector (RID). Supernatant samples $(10 \mu \mathrm{L})$ as described above were injected into the column with a mobile phase $(75 \%$ acetonitrile and $25 \%$ water) at a flow rate of $1 \mathrm{~mL} / \mathrm{min}$ and oven temperature of $40{ }^{\circ} \mathrm{C}$. A serial diluted glucose and sucrose ranging from 1 to $100 \mathrm{~g} / \mathrm{L}$ were prepared for standard curves.

\section{Enzyme activity test}

All tests were conducted under anaerobic conditions. Crude cell extracts were prepared from $10 \mathrm{~mL}$ of the culture. After centrifugation at $14,000 \mathrm{rpm}$ at $4{ }^{\circ} \mathrm{C}$ for $10 \mathrm{~min}$, the cell pellets were resuspended in $0.5 \mathrm{~mL}$ of ice-cold TE buffer (10 mM Tris-HCl, 5 mM EDTA, pH 7.5). Lysis was achieved by ultrasonication on ice for 15 min using a $20 \mathrm{kHz}$ ultrasonicator (VCX 130, Sonics \& Materials Inc., CT, USA) with the following repeated steps: $5 \mathrm{~s}$ of sonication with a $10 \mathrm{~s}$ interval, set at $50 \%$ amplitude. The collected lysate was then centrifuged at $14,000 \mathrm{rpm}$ at $4{ }^{\circ} \mathrm{C}$ for $20 \mathrm{~min}$ for cell debris removal. The supernatant was used for enzymatic activity test and stored in $1 \mathrm{~mL}$ solution tube. DC protein assay Kit (BioRad, USA) was used to determine protein concentration of cell extracts. The standard curve of NADPH was prepared using diluted $1 \mathrm{mM}$ NADPH Standard 1:5 to $0.2 \mathrm{mM}$ NADPH by adding $20 \mu \mathrm{L}$ NADPH Standard to $80 \mu \mathrm{L}$ Assay Buffer. Then, 10, 20, 30, $40 \mu \mathrm{L}$ of the $0.2 \mathrm{mM}$ NADPH Standard were added into a series of wells in a 96-well plate to generate 2, 4, 6, 8 nmole/well NADPH standards. Finally, the volume was adjusted to $50 \mu \mathrm{L}$ with
ADH1-NADP Assay Buffer. sAdhE activity was assayed by monitoring the oxidation of NADPH at $340 \mathrm{~nm}$. The $\mathrm{NADPH}$-dependent reaction was examined at $\mathrm{pH} 8.0$ under the following conditions: $0.4 \mathrm{mM} \mathrm{NADPH}, 50 \mathrm{mM}$ acetone, $35 \mathrm{mM}$ Tris chloride ( $\mathrm{pH} 8.0$ ), and crude extract (60-600 $\mu \mathrm{g}$ of protein). Final reaction volume was $600 \mu \mathrm{L}$. The change in absorbance of blank reactions without acetone was subtracted from the total. The reaction was initiated by the addition of the cell extract. One unit of specific enzymatic activity was defined as the amount of enzyme which oxidized 1 umol NADPH per minute per milligram of protein at $30{ }^{\circ} \mathrm{C}$ under the given conditions. All values of enzymatic activity test were averaged values of at least two independent extract procedures.

\section{Genome sequence analysis}

The genomic DNA of $C$. beijerinckii BGS1 was sequenced using high-throughput Illumina HiSeq2000 sequencing platform in Beijing Genomics Institute (BGI), Shenzhen, China. The platform generated 17,509,102 reads with 488 insert sizes, totaling $8544 \mathrm{Mbp}$ and providing 90 -fold coverage. To determine the difference between sequenced species and reference species through average depth and coverage ratio calculation, the raw reads were firstly aligned to reference sequence $(C$. beijerinckii NCIMB 8052) by SOAPaligner (version 2.21). Then, the filtered reads were assembled using the SOAPdenovo program (version 2.04), producing a genome size of 5,885,271 bp with 117 contigs and an $N_{50}$ length of 192,477 bp. Finally, 105 scaffolds with a maximum length of 414,297 bp were obtained through combining these contigs after contamination screening by NCBI. The draft genome was initially annotated by NCBI Prokaryotic Genome Annotation Pipeline (See http://www.ncbi. nlm.nih.gov/genome/annotation_prok/). In addition, Rapid Annotation using Subsystems Technology (RAST) server was used to depict the subsystem distribution of functional annotation results and also analyze the difference of protein sequences [35]. In RAST server, the tRNA genes were identified by tRNAscan-SE [36] and the rRNA encoding genes were identified using a tool "search_for_ RNAs" [37]. Putative protein-encoding genes were initially called by GLIMMER3 [38] and then analyzed by BLASTP and BLASTX [39]. Lastly, the predicated functions of protein-encoding genes were annotated through a set of subsystem-based FIGfams protein database [37].

Average nucleotide identity (ANI), a measure of the pairwise average nucleotide identity shared between two genomes, was multi-analyzed using Jspecies software [40]. 15 genome sequences of Clostridium species including BGS1 were selected for ANI calculation based on MUMmer package [41]. All genome sequences are 
Table 3 Primers for genes sAdhE and AdhE2

\begin{tabular}{lll}
\hline Gene & Primer forward & Primer reverse \\
\hline sAdhE & 5'-AAT CAT GGC AGG TGG AGG TG-3' & 5'-TTT CTG CTC GTA AAC GCC CT-3' \\
AdhE2 & 5'-TAT TAG CCA CTG GAG GTC CAG G-3' & 5'-CGC AAA CTA CCC CGT TAT CAA-3'
\end{tabular}

fragmented into 1020 bp regions which are then compared with those of the other species.

To analyze the expression of two specific genes encoding secondary alcohol dehydrogenase (sAdhE) and alcohol dehydrogenase (AdhE2) responsible for isopropanol and ethanol production, respectively, quantitative realtime PCR (qPCR) was used in this study. Primers used in this experiment are shown in Table 3. At every sampling time, $1 \mathrm{~mL}$ of cultures was harvested by centrifuging at $14,000 \mathrm{rpm}$ and $4{ }^{\circ} \mathrm{C}$ for $10 \mathrm{~min}$. Total RNA was then extracted from the resulting pellets using a combined Trizol and RNeasy Mini Kit (Qiagen, Hilden, Germany) according to manufacturer's protocol. RNase-free DNase Kit (Qiagen, Hilden, Germany) was used to remove potentially environmental genomic DNA. Corresponding cDNA was generated from extracted RNA using a High Capacity cDNA Reverse Transcription Kit (Applied Biosystems) with RNase inhibitor and random hexanucleotide primer (both from Promega). cDNA samples were used as DNA templates for qPCR amplification using an ABI 7500 Fast real-time PCR system (ABI, Foster City, CA) with QuantiTect SYBR Green Kit (Qiagen, GmBH, Germany). To calculate the relative abundance, cycle to threshold value (Ct value) of each target gene was normalized to the abundance of the 16S rRNA gene for comparison. The final results were expressed as fold copies by normalizing lowest point of the relative abundance.

\section{Nucleotide sequence accession number}

This Whole Genome Shotgun project has been deposited at DDBJ/ENA/GenBank under accession number MBAF00000000.

\footnotetext{
Abbreviations

ABE: acetone-butanol-ethanol; adc: acetoacetate decarboxylase; AdhE: alcohol dehydrogenase; ANI: average nucleotide identity; BdhE: butanol dehydrogenase; CDSs: coding sequences; IBE: isopropanol-butanol-ethanol; MV: methyl viologen; NAD: nicotinamide adenine dinucleotide; NADP: nicotinamide adenine dinucleotide phosphate; RAST: Rapid Annotation using Subsystems Technology; RSM: response surface method; sAdhE: secondary alcohol dehydrogenase; VFAs: volatile fatty acids.
}

\section{Authors' contributions}

CZ designed the study, executed all the experiment works, analyzed the data and wrote the draft manuscript. TL assisted the experiment design, manuscript review and fermentation data analysis. JH contributed to the study design, data analysis and manuscript revision. All authors read and approved the final manuscript.

\section{Acknowledgements}

This research was supported by the National Research Foundation, Prime Minister's Office, Singapore under the Competitive Research Programme with a Project No.: NRF-CRP5-2009-05 and the Ministry of Education, Singapore under Academic Research Fund with a Project No.: R-302-000-148-112.

\section{Competing interests}

The authors declare that they have no competing interests.

\section{Availability of data and materials}

All data generated or analyzed during this study are included in this published article.

\section{Consent for publication \\ Not applicable.}

Ethics approval and consent to participate

Not applicable.

\section{Publisher's Note}

Springer Nature remains neutral with regard to jurisdictional claims in published maps and institutional affiliations.

Received: 26 June 2018 Accepted: 26 September 2018

Published online: 11 October 2018

\section{References}

1. Gu Y, Jiang Y, Wu H, Liu X, Li Z, Li J, Xiao H, Shen Z, Dong H, Yang Y. Economical challenges to microbial producers of butanol: feedstock, butanol ratio and titer. Biotechnol J. 2011;6:1348-57.

2. Lee I, Johnson LA, Hammond EG. Use of branched-chain esters to reduce the crystallization temperature of biodiesel. J Am Oil Chem Soc. 1995;72:1155-60.

3. Rassadin V, Shlygin OY, Likhterova N, Slavin V, Zharov A. Problems in production of high-octane, unleaded automotive gasolines. Chem Technol Fuels Oils. 2006;42:235-42.

4. Cho C, Jang Y-S, Moon HG, Lee J, Lee SY. Metabolic engineering of clostridia for the production of chemicals. Biofuels Bioprod Biorefin. 2015:9:211-25.

5. Jones DT, Woods DR. Acetone-butanol fermentation revisited. Microbiol Rev. 1986;50:484.

6. Lee J, Jang Y-S, Choi SJ, Im JA, Song H, Cho JH, Papoutsakis ET, Bennett GN, Lee SY. Metabolic engineering of Clostridium acetobutylicum ATCC 824 for isopropanol-butanol-ethanol fermentation. Appl Environ Microbiol. 2012;78:1416-23.

7. Lehmann D, Hönicke D, Ehrenreich A, Schmidt M, Weuster-Botz D, Bahl H, Lütke-Eversloh T. Modifying the product pattern of Clostridium acetobutylicum. Appl Microbiol Biotechnol. 2012;94:743-54.

8. Osburn O, Brown R, Werkman C. The butyl alcohol-isopropyl alcohol fermentation. J Biol Chem. 1937;121:685-95.

9. Li Y, Meng L, Nithyanandan K, Lee TH, Lin Y, Chia-fon FL, Liao S. Combustion, performance and emissions characteristics of a spark-ignition engine fueled with isopropanol- $n$-butanol-ethanol and gasoline blends. Fuel. 2016;184:864-72.

10. Chen J-S, Hiu SF. Acetone-butanol-isopropanol production by Clostridium beijerinckii (synonym, Clostridium butylicum). Biotech Lett. 1986;8:371-6. 
11. Lee SY, Park JH, Jang SH, Nielsen LK, Kim J, Jung KS. Fermentative butanol production by Clostridia. Biotechnol Bioeng. 2008;101:209-28.

12. George HA, Johnson JL, Moore WE, Holdeman LV, Chen JS. Acetone, isopropanol, and butanol production by Clostridium beijerinckii (syn. Clostridium butylicum) and Clostridium aurantibutyricum. Appl Environ Microbiol. 1983:45:1160-3.

13. Máté de Gérando H, Wasels F, Bisson A, Clement B, Bidard F, Jourdier $E$, López-Contreras AM, Lopes Ferreira N. Genome and transcriptome of the natural isopropanol producer Clostridium beijerinckii DSM6423. BMC Genomics. 2018;19:242.

14. Miller NJ, Garrett OW, Prickett PS. Anaerobic technique-a modified deep agar shake. J Food Sci. 1939;4:447-51.

15. Goris J, Konstantinidis KT, Klappenbach JA, Coenye T, Vandamme P, Tiedje JM. DNA-DNA hybridization values and their relationship to wholegenome sequence similarities. Int J Syst Evol Microbiol. 2007:57:81-91.

16. Stackebrandt E, Goebel B. Taxonomic note: a place for DNA-DNA reassociation and $16 \mathrm{~S}$ rRNA sequence analysis in the present species definition in bacteriology. Int J Syst Evol Microbiol. 1994;44:846-9.

17. Lee S-M, Cho MO, Park CH, Chung Y-C, Kim JH, Sang B-I, Um Y. Continuous butanol production using suspended and immobilized Clostridium beijerinckii NCIMB 8052 with supplementary butyrate. Energy Fuels. 2008;22:3459-64.

18. Chen J-S. Alcohol dehydrogenase: multiplicity and relatedness in the solvent-producing clostridia. FEMS Microbiol Rev. 1995;17:263-73.

19. Li M, Liao X, Zhang D, Du G, Chen J. Yeast extract promotes cell growth and induces production of polyvinyl alcohol-degrading enzymes. Enzyme Res. 2011;2011:179819.

20. Bezerra MA, Santelli RE, Oliveira EP, Villar LS, Escaleira LA. Response surface methodology (RSM) as a tool for optimization in analytical chemistry. Talanta. 2008;76:965-77.

21. Sellick CA, Campbell RN, Reece RJ. Chapter 3 Galactose metabolism in yeast-structure and regulation of the leloir pathway enzymes and the genes encoding them. In: Jeon KW, editor. International review of cell and molecular biology, vol. 269. Cambridge: Academic Press; 2008. p. $111-50$.

22. Youn SH, Lee KM, Kim K-Y, Lee S-M, Woo HM, Um Y. Effective isopropanolbutanol (IB) fermentation with high butanol content using a newly isolated Clostridium sp. A1424. Biotechnol Biofuels. 2016;9:230.

23. Görke B, Stülke J. Carbon catabolite repression in bacteria: many ways to make the most out of nutrients. Nat Rev Microbiol. 2008;6:613-24.

24. Krzywinski M, Schein J, Birol I, Connors J, Gascoyne R, Horsman D, Jones SJ, Marra MA. Circos: an information aesthetic for comparative genomics. Genome Res. 2009;19:1639-45.

25. Xin F, He J. Characterization of a thermostable xylanase from a newly isolated Kluyvera species and its application for biobutanol production. Bioresour Technol. 2013;135:309-15.
26. Li R-D, Li Y-Y, Lu L-Y, Ren C, Li Y-X, Liu L. An improved kinetic model for the acetone-butanol-ethanol pathway of Clostridium acetobutylicum and model-based perturbation analysis. BMC Syst Biol. 2011;5:S12.

27. El Kanouni A, Zerdani I, Zaafa S, Znassni M, Loutfi M, Boudouma M. The improvement of glucose/xylose fermentation by Clostridium acetobutylicum using calcium carbonate. World J Microbiol Biotechnol. 1998;14:431-5.

28. Ujor V, Agu C, Gopalan V, Ezeji T. Glycerol supplementation enhances furfural detoxification by Clostridium beijerinckii during butanol fermentation. Appl Microbiol Biotechnol. 2014;98:6511-21.

29. Ujor V, Okonkwo C, Ezeji TC. Unorthodox methods for enhancing solvent production in solventogenic Clostridium species. Appl Microbiol Biotechnol. 2016;100:1089-99.

30. Merrill MD. An expert system for instructional design. IEEE Expert. 1987;2:25-37.

31. R Core Team. R: a language and environment for statistical computing. Vienna: R Foundation for Statistical, Computing; 2017.

32. Huber W, Carey VJ, Gentleman R, Anders S, Carlson M, Carvalho BS, Bravo HC, Davis S, Gatto L, Girke T. Orchestrating high-throughput genomic analysis with Bioconductor. Nat Methods. 2015;12:115.

33. Schliep KP. Phangorn: phylogenetic analysis in R. Bioinformatics. 2011;27:592.

34. Kolde R: pheatmap: Pretty Heatmaps. R package version 1.0.8.; 2015. https ://CRAN.R-project.org/package=pheatmap

35. Overbeek R, Olson R, Pusch GD, Olsen GJ, Davis JJ, Disz T, Edwards RA, Gerdes S, Parrello B, Shukla M, et al. The SEED and the rapid annotation of microbial genomes using subsystems technology (RAST). Nucleic Acids Res. 2014:42:D206-14.

36. Lowe TM, Eddy SR. tRNAscan-SE: a program for improved detection of transfer RNA genes in genomic sequence. Nucleic Acids Res. 1997;25:955-64.

37. Aziz RK, Bartels D, Best AA, DeJongh M, Disz T, Edwards RA, Formsma K, Gerdes S, Glass EM, Kubal M, et al. The RAST Server: rapid annotations using subsystems technology. BMC Genomics. 2008;9:75.

38. Delcher AL, Harmon D, Kasif S, White O, Salzberg SL. Improved microbial gene identification with GLIMMER. Nucleic Acids Res. 1999;27:4636-41.

39. Altschul SF, Madden TL, Schäffer AA, Zhang J, Zhang Z, Miller W, Lipman DJ. Gapped BLAST and PSI-BLAST: a new generation of protein database search programs. Nucleic Acids Res. 1997;25:3389-402.

40. Richter M, Rosselló-Móra R. Shifting the genomic gold standard for the prokaryotic species definition. Proc Natl Acad Sci. 2009;106:19126-31.

41. Kurtz S, Phillippy A, Delcher AL, Smoot M, Shumway M, Antonescu C, Salzberg SL. Versatile and open software for comparing large genomes. Genome Biol. 2004;5:R12.

\footnotetext{
Ready to submit your research? Choose BMC and benefit from:

- fast, convenient online submission

- thorough peer review by experienced researchers in your field

- rapid publication on acceptance

- support for research data, including large and complex data types

- gold Open Access which fosters wider collaboration and increased citations

- maximum visibility for your research: over 100M website views per year
}

At BMC, research is always in progress.

Learn more biomedcentral.com/submissions 